\title{
A construção da imagem do Brasil no exterior: um estudo sobre as rotinas profissionais dos correspondentes internacionais
}

Shaping the Brazilian international image: a study on the foreign correspondents' reporting routines

ANTONIO BRASIL

Professor do Programa de Pós-Graduação em Jornalismo da Universidade Federal de Santa Catarina - (UFSC).

<antonibrasil@gmail.com>

\section{RESUMO}

Este trabalho tem como objetivo analisar o papel do jornalismo na construção do imaginário internacional. O fundamento teórico recorre aos conceitos de Antropojornalismo, Agenda Setting e Gatekeeping de autores emblemáticos como Hannerz, Said e Gans. O conteúdo empírico é resultado de pesquisas acadêmicas recentes e da longa trajetória profissional do autor como correspondente internacional na Europa e na América Latina. Acreditamos na hipótese de que a produção jornalística dos correspondentes e das agências de notícias, principalmente aquelas que formam o segmento televisivo, tem papel fundamental na construção da imagem do Brasil no exterior. Essa produção, no entanto, reflete um processo de autorreferencialidade ao privilegiar a imprensa brasileira como fonte primária de notícias utilizadas pelos correspondentes estrangeiros baseados no país.

PAlavras-chave: Jornalismo internacional; Correspondentes estrangeiros; Agências internacionais; Imaginário nacional; Autorreferencialidade.

\begin{abstract}
This paper analyzes the role of foreign correspondents in shaping Brazilian international imagery. The theoretical foundation draws on the concepts of Anthrojournalism, Agenda Setting and Gatekeeping elaborated by distinguished author as Hannerz, Said and Gans. The empirical content is a result of recent academic research and the author's long career as a foreign correspondent in Europe and Latin America. The study addresses the production of the foreign correspondents in international news agencies based in Brazil, especially those journalists in the television segment. They have a key role in constructing and projecting Brazilian image abroad. However, their news production reflects a communication process of self-referentiality that uses the Brazilian press as a primary source for news correspondents who work in the country.
\end{abstract}

KeYwoRds: International news; Foreign correspondents; News agencies; National imagery; Self-referentiality. 
As principais agências internacionais de notícias apresentam o Brasil como uma nação assombrosa, oscilando entre paraíso tropical e inferno dantesco."

(Peter Burke, 2006)

Em face de reportagem leviana, mentirosa e ofensiva à honra do Presidente da República Federativa do Brasil, com grave prejuízo à imagem do país no exterior, publicada na edição de 9 de maio passado do jornal The New York Times, o Ministério da Justiça considera, nos termos do artigo 26 da Lei $n^{0}$ 6.815, inconveniente a presença em território nacional do autor do referido texto. Nessas condições, determinou o cancelamento do visto temporário do Sr. William Larry Rohter Junior ${ }^{1 . "}$

\begin{abstract}
A polêmica matéria, citada acima, do correspondente no Brasil do The New York

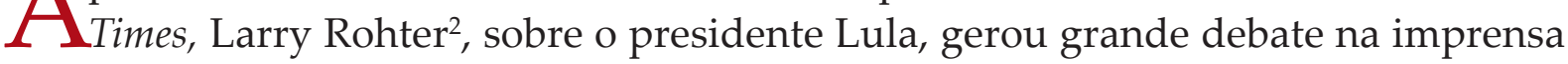
sobre os direitos e os limites impostos aos profissionais estrangeiros que cobrem o nosso país. Opiniões contrárias e a favor do artigo e da decisão do governo brasileiro de expulsar o jornalista foram amplamente divulgadas na imprensa dos dois países durante meses e ainda são discutidas em diversos trabalhos acadêmicos ${ }^{3}$.

A matéria de Larry Rohter e a reação do governo brasileiro também propiciaram uma oportunidade singular para refletirmos sobre as rotinas de trabalho da comunidade dos correspondentes que trabalham no Brasil e o papel da mídia internacional na divulgação de notícias sobre o nosso país. A reportagem do The New York Times
\end{abstract}


permite-nos avaliar o grau de importância aferido pelo governo brasileiro à construção e à possível manipulação ou controle da imagem do Brasil no exterior. Naquela ocasião, foram divulgadas e analisadas ações ou estratégias que visam influenciar a construção dessa imagem pelos jornalistas e pela mídia ${ }^{4}$.

Nessa perspectiva, procuramos pesquisar as estratégias possíveis para a construção ou manipulação do imaginário nacional pelos jornalistas internacionais. A nossa principal investigação concentra-se na hipótese de que a imagem de um país é produto do noticiário internacional, principalmente, do noticiário televisivo. Também procuramos confirmar a hipótese secundária de que a imagem do Brasil no exterior é um processo de autorreferencialidade que se confunde com a nossa própria identidade nacional.

Nossos estudos sobre a construção da imagem do Brasil no exterior pelos correspondentes internacionais procuram confirmar processos semelhantes que acontecem nos demais países. Afinal, o que sabemos sobre outros países como o Iraque, o Irã, o Afeganistão ou a Noruega? Qual é a imagem que temos desses países? A maior parte das informações que obtemos sobre essas nações tem origem primária no Jornalismo, principalmente na TV em seu segmento jornalístico: os telejornais.

Procuramos investigar os processos produtivos praticados pela comunidade dos correspondentes estrangeiros, divulgados pelas principais agências internacionais de notícias. Eles seriam responsáveis pela construção de uma parcela significativa do imaginário, não somente do Brasil, mas de todos os países. O problema, no entanto, é reconhecer que nenhuma imagem é completamente objetiva ou inocente (Gazut apud Brasil, 2007).

\section{Referências históricas e teóricas}

O Jornalismo como atividade profissional já teria nascido internacionalmente em seus primórdios, pois os veículos de imprensa pioneiros - originados no contexto 
da ascensão da burguesia na Europa nos séculos XVII e XVIII - foram criados principalmente para informar leitores locais (em grande parte, comerciantes e banqueiros) sobre fatos acontecidos no exterior.

Chama-se Jornalismo Internacional a especialização da profissão jornalística focada nos eventos estrangeiros em relação ao país onde está sediado o veículo de imprensa em que o jornalista trabalha. Por isso, a definição é relativa por natureza: o que é assunto "doméstico" num determinado país será "internacional" em todos os demais. Essa peculiaridade faz com que o Jornalismo Internacional seja provavelmente a área do Jornalismo com maior abrangência de temas entre todas as outras, já que deve dar conta de política, economia, cultura, acidentes, natureza e todos os assuntos que aconteçam fora de seu país de origem. A imagem do Brasil no exterior é em boa parte produto do trabalho dos correspondentes estrangeiros. Eles trabalham diariamente para enviar notícias sobre o país.

O correspondente é um repórter fixado numa cidade estrangeira - muitas vezes a capital de um país -, sendo responsável por uma região, um país ou, às vezes, até um continente inteiro. Ele deve enviar matérias regularmente para a redação da sede de seu veículo. Para isso, ele acompanha toda a imprensa local, mantém contatos frequentes com jornalistas e colegas correspondentes e identifica fontes estratégicas - como entidades, governos, diplomatas, militares e outras que possam fornecer informações importantes. Na maior parte das vezes, o correspondente é autopautado - ou seja, ele mesmo define o que selecionar, escrever e apurar. O correspondente deve ter conhecimento profundo da realidade local e um talento discricionário elevadíssimo para identificar os fatos mais relevantes no país onde trabalha, que sejam, ao mesmo tempo, interessantes para seu país de origem.

No Brasil, desde a sua descoberta até o século XIX, predominou uma imagem associada à grandeza de território, abundância de vida selvagem e sensualidade, 
como dotes naturais - graças aos relatos que começaram pela carta de Pero Vaz de Caminha e por outros tantos viajantes e colonizadores que por aqui passaram. Já como dotes adquiridos, destacam-se o desenvolvimento da vida urbana, malandragem, jeito brasileiro, indolência, musicalidade e cordialidade - isso não é apenas pensamento do estrangeiro, mas uma visão projetada pelos brasileiros.

O Brasil historicamente apresentado na mídia estrangeira é invariavelmente fruto de uma imaginação desbragada sobre os trópicos e de uma projeção de uma utopia cheia de estereótipos e clichês, nos quais prevalecem velhos modelos de representação, calcados na exploração de uma natureza exuberante e de costumes singulares frente ao olhar euro-americano. Trata-se de um repertório de imagens que remonta aos anos de 1930, quando o Brasil ingressava na rota do turismo a partir dos grandes cruzeiros, dos cassinos e da reprodução internacional de um imaginário de um povo cordial e com manifestações culturais particulares. A beleza das mulheres, a musicalidade das gentes e o carnaval são expressões que seriam agregadas à descoberta da Amazônia e, mais recentemente, à violência e à exclusão, numa linha de desenvolvimento histórico que representa a imagem que temos do país.

Em relação às referências teóricas, este estudo procura convergir com os conceitos da Antropologia e do Jornalismo, sob a égide do Antropojornalismo (Said, 2003). Trata-se da combinação da prática e dos valores ético-profissionais do jornalismo com os objetivos investigativos das técnicas etnográficas da Antropologia. Hannerz (2004) enfatiza a importância da convergência entre a Antropologia e o Jornalismo. Ele argumenta que deveríamos investigar nossas rotinas de trabalho da mesma forma e com o mesmo rigor que investigamos os demais grupos sociais. $\mathrm{O}$ Antropojornalismo busca integrar o jornalista-antropólogo, ou vice-versa, nas comunidades a serem investigadas. A proximidade entre o Jornalismo e a Antropologia é uma proposta 
promissora. As duas profissões, de formas diversas, possuem interesses comuns. Porém, a sua confluência ou cumplicidade pode gerar novos campos de interesse tanto para uma área quanto para a outra ${ }^{5}$.

Em seu livro Foreign News, Exploring the World of Foreign Correspondents, Ulf Hannerz (2004) dirige seu olhar antropológico para descrever os hábitos, costumes e segredos dos jornalistas internacionais. Qual seria o verdadeiro papel social daqueles profissionais que se dedicam a nos mostrar o melhor e o pior de um mundo? Como eles enfrentam os desafios de um planeta globalizado cada vez menor, porém mais complicado e quase incompreensível? Será que os correspondentes estrangeiros e o Jornalismo Internacional estariam em extinção? O trabalho metódico e cuidadoso do antropólogo sueco não se limita a temas considerados polêmicos. Ele teve a paciência e a dedicação para buscar as características comuns e as diversidades da tribo dos correspondentes estrangeiros; também investigou a formação acadêmica - ou a falta de - desses jornalistas, seus interesses literários, suas práticas profissionais e suas principais referências históricas como os heróis mitológicos da profissão.

Correspondentes ou jornalistas internacionais contribuem para criar a imagem do Brasil no exterior, o Brasil com Z. Além de noticiar os grandes desastres ou acontecimentos, eles também mostram regularmente tudo o que nós já nos acostumamos. Convivemos com um noticiário repleto de fatos e situações considerados normais ou naturais. Mas, para o olhar ampliado de um estrangeiro, nossa realidade é um grande manancial de notícias. Eles só precisam abrir os jornais ou assistir à televisão regularmente para testemunhar questões sociais, políticas e econômicas que se repetem regularmente, transformando-se em imagens ou estereótipos no exterior. No entanto, os jornalistas costumam dar preferência às notícias ruins. É da natureza da profissão. 


\section{Agências internacionais de notícias}

As agências de notícias são empresas jornalísticas especializadas em difundir informações e notícias diretamente das fontes para os veículos de mídia. As agências operam por meio de escritórios locais, em diferentes cidades e países, que transmitem sua apuração para as centrais, as quais, por sua vez, redistribuem o material para os clientes (jornais, revistas, rádios, televisões, websites etc.). As agências surgiram em meados do século XIX com a fundação da Havas (mais tarde dividida entre AFP e Reuters). Durante a Guerra Civil Americana nos Estados Unidos, os maiores jornais de Nova York juntaram-se para formar a Associated Press e enviar um pool de correspondentes para o campo de batalha. Hoje, as agências mantêm uma rede de correspondentes e stringers (colaboradores) nas maiores cidades do mundo, repassando, assim, informações para os veículos de imprensa. Nos últimos anos, o trabalho das agências e de seus correspondentes foi enormemente facilitado pelas chamadas Novas Tecnologias de Informação e Comunicação (NTICs), como a internet.

Em relação ao fluxo comunicacional internacional, para Edward Said (1993), historicamente, os meios de comunicação americanos, e talvez os ocidentais de maneira geral, têm sido extensões sensoriais do contexto cultural predominante. O poder das agências internacionais e o seu peso no estabelecimento da agenda informativa internacional são seguidos pela imprensa local. Mais adiante, Said declara:

O sistema de mídia internacional tem feito, na realidade, aquilo que pretenderiam fazer as noções idealistas ou ideológicas de coletividade, de comunidade imaginária... Em comparação à forma como operam as quatro grandes agências de notícias ocidentais, à maneira pela qual os telejornalistas internacionais de língua inglesa selecionam, reúnem e transmitem imagens pictóricas de todo o mundo, a mídia não é apensas uma rede prática totalmente integrada, mas um modo de articulação eficientíssimo unindo o mundo inteiro."

(Said, 1993, pp. 379-380) 
A influência das agências de notícias internacionais no noticiário local e na construção de uma imagem ou identidade nacional também é um vetor importante da nossa pesquisa.

Para Said,

os meios de comunicação são fundamentais para a cultura doméstica... agora temos de acréscimo uma presença internacional dos meios de comunicação, a qual se insinua, muitas vezes em nível subliminar, num campo fantasticamente amplo. A expressão imperialismo cultural... ganha pertinência quando vista numa perspectiva global."

(Said, 2003, p. 45)

Em suas pesquisas sobre identidade nacional, Maria Cristina Caponero critica a produção das agências internacionais e denuncia a reafirmação de estereótipos:

Muitas vezes justifica-se a imagem de um país pela divulgação feita pelos meios de comunicação em geral e pela imprensa estrangeira internacional, que recebe as notícias das principais agências noticiosas internacionais como Reuters, United Press International (UPI), e Associated Press (AP), as quais manipulam e alteram as informações, exercendo uma seleção arbitrária da informação e uma avaliação tendenciosa da realidade expondo determinados problemas nacionais, o que significa dizer que as notícias do mundo são etnocêntricas, refletem a opinião da Europa e dos Estados Unidos, e estão carregadas de elementos estereotipados, imagens, ideias e conceitos que nem sempre representam a realidade, mas que acabam sendo aceitas pelas pessoas que as tomam como reais tornando de um certo modo um consenso sobre uma imagem veiculada a respeito de algo ou algum país."

(Caponero, 2007, p. 86) 
Em relação ao caso específico do Brasil, Murta e Goodey consideram que

essa imagem estereotipada dos países tem aceitação no próprio território nacional: ela é assumida como elemento verdadeiro da cultura brasileira e dessa forma é difundida. [...] Dessa forma, há que se reconhecer a importância dos meios de comunicação de massa, sem desconsiderar a existência de uma visão estereotipada que nós mesmos assumimos para nos apresentarmos ao mercado internacional."

(Murta e Goodey apud Caponero, 2007, p. 87)

Em relação ao meio televisivo, Esperidião descreve as rotinas jornalísticas das agências internacionais:

O detalhamento das práticas operacionais as agências que aqui se conclui permite sustentar que a Reuters TV e APTN irrigam o sistema noticioso audiovisual continuamente. As duas empresas globais sanam os problemas das emissoras mundiais e se comportam, sem constrangimento, como atravessadoras da notícia: trocam, compram, produzem e fazem intermediações. Em sintese, vendem a ideia de uma garantia de cobertura, embora uma cobertura circunstanciada por múltiplas tensões e controvérsias, notadamente pelas escolhas editoriais ligadas às superpotências mundiais."

(Esperidião, 2011, p. 207) 
Nesse cenário, ao contrário do que gostariam muitos governos que fazem grandes investimentos de recursos públicos em campanhas para garantir a difusão de notícias consideradas "positivas" sobre seus países, os jornalistas internacionais preferem divulgar as notícias ruins, os desastres naturais ou desastres produzidos pelos homens. Ou seja, as pautas consideradas negativas. Assim, são responsáveis pela construção da imagem dos países. Seguindo essa linha de pensamento, as reportagens produzidas pelos correspondentes e pelas agências internacionais provavelmente serão as únicas informações que o grande público receberá sobre este grande e importante país da América Latina chamado Brasil.

Nossa hipótese é de que a imagem do Brasil no exterior é resultado da nossa própria percepção sobre o nosso país. Seria produto de uma autoimagem, traduzida e divulgada pelos correspondentes baseados no país, que se utilizam do noticiário brasileiro como fonte primária para a formatação da imagem do Brasil no exterior. Ou seja, apesar dos estereótipos culturais dos próprios correspondentes, são os próprios brasileiros que forneceriam a matéria-prima para o noticiário internacional sobre o nosso país.

\section{Rotinas profissionais}

Nossas pesquisas buscam responder questões sobre os critérios de noticiabilidade que a imprensa estrangeira usa para definir o que e quem é notícia no Brasil. Em certo sentido, os brasileiros seriam cúmplices dos estrangeiros na criação de uma autoimagem. Poderíamos até dizer que, no caso dos mitos de nações ou povos, de maneira geral, os estereótipos externos não são inteiramente distintos dos estereótipos locais ou nativos. Pelo contrário: os dois tipos de estereótipos geralmente interagem. Por outro lado, estaríamos diante de um paradoxo. Hoje, os correspondentes estrangeiros também são brasileiros. Acreditamos que seria importante estudar o olhar estrangeiro lançado sobre a realidade nacional cotidianamente pela mídia estrangeira, traçando comparativos e 
analisando estereótipos comuns. Essas investigações poderiam ser uma maneira contínua de colaborar com a prevenção de outras produções jornalísticas ou audiovisuais equivocadas, focadas apenas nos estereótipos de "país do futebol e do Carnaval".

Em nossas pesquisas, procuramos analisar temas recorrentes sobre o Brasil na imprensa internacional. Com certeza, os temas ambientais, a redução da pobreza e das desigualdades e a posição brasileira na política internacional serão sempre manchetes. Este trabalho procura responder como o correspondente pode estabelecer normas consideradas positivas ou negativas para a formatação da imagem do Brasil no exterior.

\section{Metodologia e análise de dados}

Nosso estudo está voltado essencialmente para uma investigação e análise da cobertura do Brasil pelas agências internacionais. Acreditamos que as agências internacionais são a fonte primária de acesso às informações sobre o nosso país, que, em última instância, são responsáveis pela construção e desconstrução da tão citada e polêmica imagem do Brasil no exterior. Como a televisão ainda é o principal meio de comunicação da atualidade, concentraremos o foco da pesquisa nas agências internacionais de notícias para a TV, a destacar:

1. Asociated Press Television News (APTN)

2. Thompson-Reuters (Reuters TV)

$\mathrm{O}$ material coletado em pesquisas diretas nos arquivos das agências de notícias internacionais foi escolhido como locus do nosso estudo; será reunido e integrado por meio de um processo de análise-síntese das matérias produzidas sobre o Brasil. O objetivo desta estratégia de pesquisa é constar as dificuldades e as barreiras que venham a emergir juntamente com outras informações consideradas mais relevantes para a própria finalidade da pesquisa. Podem surgir, nessa etapa, indícios sobre a necessidade de realização de levantamentos complementares, a serem discriminados 
quando for constatada essa carência. "A eficácia está na elaboração contraditória de dados, que a sua forma seja transmissível e que seu acesso fácil permita que esses dados sejam criticados. Não é suficiente que sejam geralmente aceitos como objetivos" (Thiollient, 2009, p. 12).

Não se pretende esgotar o assunto, mas recolher dados e elementos a serem considerados para futuras pesquisas. A informação colhida junto a diversos jornalistas, editores e técnicos especializados em arquivos jornalísticos de várias agências internacionais de noticias constituem a nossa base de pesquisa. O levantamento seletivo dos dados, sobre o modelo de transferência de informação em diversas instituições e empresas especializadas em armazenamento de matérias sobre o Brasil. Por outro lado, podemos aproveitar a proposta de investigação sobre a imagem do Brasil no exterior para incentivar uma análise da função e responsabilidade social da Ciência e da imprensa.

\section{APTN}

Em relação às grandes agências internacionais de notícias para TV, estamos diante de números significativos. Segundo Esperidião (2011, p. 125),

a APTN tem 89 escritórios em 67 países; a Reuters TV 85 em 60 países. A APTN tem cerca de 550 clientes instalados em 113 países e alega que alimenta $88 \%$ do conteúdo emanado pelas emissoras do mundo. A Reuters TV tem 611 clientes em 108 países. Em 2007, a Reuters disse ter produzido quase dois bilhões e meio de manchetes no mundo foi vista por 1 bilhão de pessoas, distribuindo 54 mil vídeos. A Associated Press Television News diz que chega a ser vista por metade da população mundial em um único dia." 
Foram analisadas matérias produzidas por correspondentes de agências internacionais de notícias para TV em períodos diversos. O objetivo é buscar uma amplitude comparativa dentro da amostra da pesquisa. As reportagens foram obtidas através de acesso aos arquivos das agências, por meio de busca por país e assunto. As reportagens selecionadas permitem um trabalho estatístico representativo. A análise das reportagens segue os princípios da análise crítica de conteúdo.

O fluxo de notícias internacionais destinado às emissoras de televisão é comandado principalmente por três grandes jogadores da arena midiática:

1. A APTN e a Reuters TV, que vendem imagens para seus clientes, sejam eles portais como Terra TV, sejam emissoras de televisão, como a Rede Globo, a Rede Bandeirantes ou a rede mexicana Televisa;

2. As emissoras de televisão de alcance mundial, com vasta atuação para além de seus países de origem (SkyNews, ABC, NBC, CBS e CNN);

3. Os consórcios, cooperações e parcerias entre emissoras públicas e privadas com ou sem fins lucrativos, sendo a maior destas representada pela European Broadcasting Union (EBU).

O funcionamento das agências no Brasil é subordinado ao núcleo formado por Washington e Londres. Os escritórios brasileiros seguem as mesmas normas e rotinas das sucursais de outros países da América Latina. A APTN e a Reuters TV trocam e compram reportagens das emissoras comerciais brasileiras, cuja grade de programação dedicada ao jornalismo permite que se forneça um volume noticioso diário para as agências. Do Rio de Janeiro, o material é encaminhado para Washington, onde é editado e revisado; após o primeiro tratamento, é disseminado para Londres que, finalmente, distribui as imagens por meio de sua rede de assinantes (inclusive do Brasil) e pela EBU. 
Para Fenby (1986), são evidentes os pontos fracos na cobertura das agências. O autor explica que as pequenas equipes mantidas em países gigantescos tendem a reproduzir a notícia de segunda mão. As agências assumem percepções construídas por uma elite econômica e política, concentrada nas capitais e grandes cidades. Para o autor, ao reprocessar o que as emissoras já decidiram como notícia, as agências correm sérios riscos de simplificar, estereotipar e caricaturar países.

A partir dos anos 1989, as agencias Reuters e a APTN passaram a adotar uma política de recrutamento multicultural. Conforme relato de Esperidião,

os correspondentes nascidos e integrados à região sobre a qual produzem reflete, no limite, uma tentativa de induzir o fluxo periferia-centro, um olhar diferente sobre os acontecimentos, mesmo que os chefes com maior poder de decisão continuem sendo europeus e americanos."

(Esperidião, 2011, p. 119)

\section{Dados preliminares}

$\mathrm{Na}$ primeira fase da pesquisa foram realizadas entrevistas com correspondentes e editores internacionais da APTN além de acesso aos arquivos digitais da APTN. Também foram conduzidas análise de conteúdo em 165 matérias sobre o Brasil no período de janeiro de 2008 a janeiro de 2009. Em relação ao fundamento teórico, procuramos recorrer ao agendamento de notícias para analisar a produção das agências internacionais. Em nossas pesquisas nas bases de dados virtuais da APTN, podemos enunciar as seguintes categorias de produção de matérias jornalísticas: 
1. Hard news - notícias gerais: acidentes, desastres naturais, encontros políticos internacionais (eventuais);

2. Soft news - matérias produzidas: cultura, música, turismo, fait divers ou matérias exóticas/bizarras (programadas);

3. Matérias positivas;

4. Matérias negativas.

Dessa forma, notícias selecionadas nos arquivos digitais da APTN se enquadram nas teorias, afirmações, hipóteses e conceitos propostos. “Uma análise é válida quando a descrição quantificada que ela oferece a respeito do conteúdo é significativa para o problema original e reproduz fielmente a realidade dos fatos que ele representa" (Freitas e Janissek, 2000, p. 57). A análise procurou estar atenta aos pontos de conexão quantitativa de uma determinada categoria, permitindo análises sobre a noticiabilidade do conteúdo em relação ao veículo em que foi divulgado. Dessa forma, buscamos uma análise do conteúdo que representasse possíveis categorias próprias para as matérias produzidas pela APTN sobre o Brasil, no período de 2008 a 2009. Em relação aos enquadramentos jornalísticos, foram estabelecidas as seguintes subcategorias:

- temáticas,

- eventos

- não-eventos

Análise das categorias e das notícias enquadradas em cada uma, explicitando casos emblemáticos, com exemplos e deduções. Incluem-se, ainda, na análise qualitativa, as entrevistas com os correspondentes e editores da APTN acerca dos critérios de noticiabilidade utilizados e da decisão editorial para incluir o Brasil no noticiário internacional. Indicar exemplos e critérios paradigmáticos que possam elucidar as decisões editoriais. O resultado do cruzamento entre os dados qualitativos e 
quantitativos deve refletir nas conclusões sobre as mudanças no fluxo informativo internacional sobre o Brasil.

Os critérios que motivam determinados países a estarem presentes no cenário midiático internacional e outros não. A pesquisa concentrou-se em possíveis mudanças no imaginário internacional sobre o país. No caso da APTN, o conceito de notícia e os critérios de noticiabilidade enquadram-se na categorização, proposta por Gomis (1991), de "importante" e "interessante"; estão vinculados, também, aos interesses de seus clientes. O mundo e os acontecimentos produzidos constituem a notícia, sejam eles estranhos, bizarros, cotidianos ou inéditos.

A pesquisa realizada em matérias sobre o Brasil disponíveis nos bancos de dados das agências APTN e Thompson-Reuters pode destacar os tópicos mais recorrentes:

- Meio Ambiente - destaque: Amazônia, desmatamento, movimentos agrários; invasões de terras;

- Notícias gerais: acidentes, desastres naturais;

- Política - destaque: presidente Lula, eleições, denúncias de corrupção, movimentos trabalhistas, reuniões internacionais;

- Questões internacionais e latinoamericanas - Mercosul, segurança, tráfico de drogas, terrorismo, tráfico de mulheres, imigração ilegal, diáspora brasileira;

- Violência - destaque: Rio de Janeiro, atentados contra turistas, crimes contra menores, pedofilia;

- Economia - destaque: greves, produção industrial, agricultura, inflação, exportação;

- Esportes - seleção brasileira de futebol, campeonatos regionais, campeonato nacional; 
- Cultura, comportamento, música: novidades nacionais e repercussão de grupos estrangeiros que visitam o Brasil, moda, celebridades, modismos, excentricidades (fait divers);

- Carnaval - Rio de Janeiro, desfiles, sexo, turistas, mortes;

- Religião - destaque: religiões afrobrasileiras, avanços das igrejas protestantes, crise na Igreja Católica, aborto.

Segundo dados coletados junto à agência de notícias da Rede Globo, principal fornecedor de matérias e imagens sobre o Brasil para os correspondentes das agências internacionais APTN e Thompson-Reuters, aproximadamente $80 \%$ das imagens compradas pelas TVs e agências internacionais reportam os seguintes temas (Espiridião, 2011):

1. Violência em geral e catástrofes naturais;

2. Assuntos de natureza política (decisões do governo brasileiro, novas medidas e declarações de políticos);

3. Histórias envolvendo estrangeiros, especialmente casos ligados à violência, como assaltos, assassinatos, violações, expatriações;

4. Temas relacionados ao mundo do futebol e matérias de comportamento.

\section{Conclusões}

Neste breve relato sobre pesquisa ainda em andamento, procuramos analisar os dados obtidos junto aos correspondentes e às agências internacionais de notícias. Durante o período de observação presencial do autor da pesquisa, foi possível confirmar a hipótese inicial sobre a relevância dos correspondentes internacionais na construção da imagem do Brasil no exterior e a hipótese secundária de autorreferencialidade: a imagem do Brasil no exterior como produto de nossa autoimagem. 
Podemos constatar que uma parcela significativa das imagens do Brasil que os correspondentes das agências internacionais de notícias levam para o exterior é adquirida junto à Rede Globo, especialmente quando são matérias para a televisão. Também são produzidas algumas matérias sob encomenda das editorias em Londres e Washington, mas essas reportagens também confirmam os tópicos destacados pela pesquisa.

Os dados obtidos confirmam que as representações do Brasil no exterior são fortemente baseadas em estereótipos sobre o país do carnaval, do futebol e da violência. Essas imagens, no entanto, refletem as representações que criamos e divulgamos de nós mesmos. Ou seja, geramos e divulgamos nossos próprios estereótipos.

Por outro lado, os nossos estudos sobre o fluxo de notícias internacionais igualmente indicam a necessidade de aprofundarmos a compreensão dos processos de construção, desconstrução e controle da identidade brasileira pela mídia internacional.

Consideramos a hipótese secundária ainda em fase de aprofundamento investigativo teórico e conceitual de que a imagem nacional não seja única nem estável. Ela seria dinâmica, em constante mutação. Ao contrário do que acreditamos, seria essencialmente produto da nossa própria percepção pela mídia nacional.

Em essência, acreditamos que a influência dos agentes externos para a produção dos jornalistas internacionais é limitada. Mas ainda existe a predominância de estereótipos, confirmação de expectativas ou imagens pré-concebidas sobre o Brasil por parte dos correspondentes e editores internacionais.

No caso da análise de conteúdo das matérias sobre o Brasil produzidas pelos correspondentes e divulgadas pelas agências internacionais, percebe-se a imposição de critérios que se inserem nas características da Teoria do Agendamento. Além de noticiar os grandes desastres ou acontecimentos, os correspondentes também mostram regularmente o que nós consideramos ser a imagem do Brasil. 
As agências internacionais ainda adquirem aqui no Brasil parte considerável das imagens que serão veiculadas pelas emissoras de TV estrangeiras. As matérias produzidas tendem a confirmar as expectativas dos correspondentes e seus editores internacionais a respeito de nosso País.

Em relação à imagem do Brasil, constatamos que o grande problema é que conferimos demasiada importância e relevância a essas representações. Parafraseando Said (2003), devemos considerar que as imagens não são necessariamente "verdades". As imagens não são mais do que... Imagens. Elas pertencem a um discurso mítico, polissêmico e incontrolável. A imagem do Brasil, assim como a imagem de qualquer outro país pertence ao universo do imaginário.

\section{REFERÊNCIAS}

ALLOWS, James; WOLFF, Fausto. Detonando a Notícia: como a mídia corrói a democracia americana. Rio de Janeiro: Civilização Brasileira, 1997.

BRASIL, Antonio. Telejornalismo, internet e guerrilha tecnológica. Rio de Janeiro: LCM, 2004. . A revolução das imagens. Rio de Janeiro: LCM, 2005.

. Antimanual de jornalismo e comunicação. São Paulo: Ed. Senac-SP, 2007.

CAPONERO, Maria Cristina. A imagem do Brasil na Itália. 2007. Dissertação (Mestrado) - Escola de Comunicação e Artes, Universidade de São Paulo, São Paulo, 2007.

CASTORIADIS, Cornelius. A instituição imaginária da sociedade. Rio de Janeiro: Paz e Terra, 1982.

BRITTO, Denise F. O papel do correspondente internacional na editoria exterior. In: 26o Congresso Brasileiro de Ciências da Comunicação. Anais do 26ํㅡㄹ Congresso Brasileiro de Ciências da Comunicação. Belo Horizonte: 2003.

EMERY, E. História da Imprensa. Rio de Janeiro: Lidador, 1965.

ESPERIDIÃO, Maria Cleidejane. Gigantes invisíveis no telejornalismo mundial: agências internacionais de notícias e o ecossistema noticioso global. Brazilian Journalism Review, v. 7, n. 1, 2011.

FENBY, Jonathan. The international news service. Nova York: Schocken Books, 1986.

GANS, Herbert. Democracy and the news. Nova York: Oxford, 2003. 
GOMIS, Lorenzo. Teoria del periodismo. Barcelona: Paidós, 1991.

GOYZUETA, Verônica; OGIER, Thierry et al. (orgs.). Guerra e imprensa: um olhar crítico da cobertura da guerra do Iraque. São Paulo: Summus, 2003.

HANNERS, Ulf. Foreign news. Chicago: Chicago Press, 2004.

HERMAN, Edward; CHOMSKY, Noam. Manufacturing consent. New York: Pantheon, 1988.

HESS, Stephen. International news \& foreign correspondents. Washington: The Brookings Institution, 1996.

HOHENBERG, John. Foreign correspondence: the great reporters and their times. Syracuse: Syracuse University Press, 1995.

KNIGHTLEY, Philip. A primeira vítima: o correspondente de guerra como herói, propagandista e fabricante de mitos, da Criméia ao Vietnã. Rio de Janeiro: Nova Fronteira, 1978.

NATALI, João Batista. Jornalismo internacional. São Paulo: Contexto, 2004.

SAID, Edward. O orientalismo. São Paulo: Companhia das Letras, 2003.

. Cultura e imperialismo. São Paulo: Companhia das Letras, 1993.

THIOLLENT, Michel. Metodologia da pesquisa-ação. São Paulo: Cortez, 2009.

\section{NOTAS}

1 Disponível em: <http://www.radiobras.gov.br/>. Acesso em: 12/02/2012.

2 Brazilian Leader's Tippling Becomes National Concern. Disponível em: <http://www.nytimes.com/ 2004/05/09/world/brazilian-leader-s-tippling-becomes-national-concern.html>. Acesso em: 12.02.2012.

3 ALMEIDA, Days. Cancelamento do visto de Larry Rohter: ato de soberania ou de autoritarismo? Disponível em: <http://br.monografias.com/trabalhos-pdf903/cancelamento-do-visto/cancelamento-do-visto.pdf $>$.

4 PAGANOTTI, Ivan. O Brasil de Larry Rohter: análise da cobertura do New York Times. Disponível em: <http://www.ppgl.ufscar.br/ciad/resumos/resumo_geminal_ivanpaganotti.pdf $>$; <http://www1.folha.uol. com.br/poder/794567-governo-lula-monitora-imagem-do-brasil-no-exterior.shtml>. Acesso em: 12.02.2012. 